
HEALTH
SCIENCES
QUARTERLY
Volume : 1
Issue : 1
2021
Received: 2021-03-12
E-ISSN: 2791-6022
https://journals.gen.tr/jsp

\title{
Perceptions of cadaver in physiotheraphy students and approaches to use of cadavers for anatomy education
}

\author{
Abdulkadir Bilir ${ }^{1}$ \\ Tolga Ertekin ${ }^{2}$ \\ Hilal Guzel $^{4}$ (1) Emre Atay $^{5}$ \\ 1 Department of Anatomy, Faculty of Medicine, Afyonkarahisar Health Sciences University, Afyonkarahisar / Turkey \\ 2 Department of Anatomy, Faculty of Medicine, Afyonkarahisar Health Sciences University, Afyonkarahisar / Turkey \\ 3 Department of Anatomy, Faculty of Medicine, Afyonkarahisar Health Sciences University, Afyonkarahisar/ Turkey \\ 4 Department of Anatomy, Faculty of Medicine, Afyonkarahisar Health Sciences University, Afyonkarahisar / Turkey \\ 5 Department of Anatomy, Faculty of Medicine, Afyonkarahisar Health Sciences University, Afyonkarahisar / Turkey
}

Ozan Turamanlar ${ }^{3}$ (D)

\begin{abstract}
We aimed to determine how physiotheraphy students' percieve cadavers and what kind of approach they have adopted for use cadavers and how cadaver education has changed their feelings and emotions in anatomy education. Data form that consist twelve expressions were used for determing of students' perception about cadavers. Fifty students (100 forms) were participated in research. In the data form prepared, 12 questions were included in order to determine the approach of the students, while an expression question was included to determine the emotional question at the first encounter with the cadaver. Most of participants have adopted expression before the cadaver education was "Dead human bodies shown in public areas without educational purposes affect cadaver donation adversely." (4.52 \pm 0.79$)$. While they have adopted after the cadavers education was "Human is valuable asset. Therefore, while person was both alive or after death, value and respect must be given to the human body." (4.60 \pm 0.93$)$. When the quastionaire data (before and after) were compared, statistically significant differences were found in expression of "Dead human bodies shown in public areas without educational purposes affect cadaver donation adversely" $(p=0.037)$ and "3D modeling or working on the human models is more useful than studying on cadavers in anatomy education" ( $p=0.005)$. It was observed that the number of participations was decreased for the first expression and in contrast with increased for the second expression. Physiotheraphy students regard to cadavers for in terms of human aspect and value and attribute to him/her aspecial value in terms of contribute to education. Students who were studying on cadavers in anatomy education tend to see cadaver as an education a material. We thought that these results could be help to shape and improve the anatomy education.
\end{abstract}

Keywords: Anatomy education, cadaver, perception of students, physiotheraphy students,

Citation: Bilir A, Ertekin T, Turamanlar O, Guzel H, Atay E. Perceptions of cadaver in physiotheraphy students and approaches to use of cadavers for anatomy education. Health Sci. Q. 2021; 1(1) : 31-36. https://doi.org/10.26900/hsq.1.1.06 


\section{Introduction}

With the medical education given before graduation, it is aimed that students gain basic knowledge and skills, comprehend social ethics and gain general medical skills [1]. Human anatomy, the oldest known medical science, is defined as the most important component of medical education, and it is given to students in the form of theoretical and practical courses in the first years of medical faculties in our country [2]. In addition to basic anatomical knowledge, students are also taught to solve clinical problems that they will encounter later [3].

Advances in technology have provided many new opportunities for anatomy education. It is stated that especially anatomy practical courses are a very valuable occasion for the students of medical faculty and health sciences faculties in terms of both making a significant contribution to education and allowing them to gain a professional competence [4]. Despite the possibilities of advanced modeling and threedimensional modeling presented by technological developments, cadaver dissection continues the most important component of anatomy courses [5-7]. Although different educational methods are used in anatomy education, cadaver dissection is still at the center of anatomy courses $[8,9]$

The use of human cadavers in anatomy education is considered important in terms of enabling students to learn the human body one-to-one, touch the human body and apply some skill-oriented operations. One of the memories that students will never forget is the first encounter with the cadaver in the anatomy practical courses $[4,6]$. In this period of time, people experience conflicts about their prejudices and the concepts required by their profession. For this reason, a questionnaire study was applied on physiotherapy students to determine how they perceive cadaver, what kind of approach they adopted for cadaver use in anatomy education, and how cadaver education changed their feelings and thoughts.

\section{Materials and Methods}

Data collection forms previously used by Ögenler et al. [10] and Erbay et al. [11] were revised to determine the change in physiotherapy students' perception of cadavers and their approach to cadaver use in anatomy education. In the data form prepared, 12 questions were included in order to determine the approach of the students, while an expression question was included to determine the emotional question at the first encounter with the cadaver. The questionnaire was applied to the first-year students (50 participants) of the Department of Physiotherapy and Rehabilitation of Afyon Kocatepe University twice, before cadaver training and five weeks after cadaver training in 2017. The scale, which is prepared to determine the approaches of the participants, is 5-point Likert type. In the scale, there were five statement, including "Strongly Disagree, Disagree, Undecided, Agree, Strongly Agree", and the participants were asked to choose the one that best suits them. While the data were transferred to the computer environment, these options were recorded in the same order between 1-5 points. Result data was shown as mean, standard deviation, frequency and percentages. The distribution of the data was analyzed using the Kolmogorov Smirnov test, and the Paired Samples T test was used for subgroup comparisons. The question determining the emotional expression at the moment of encountering the cadaver was shown in percentages according to the expression chosen by the students. Local clinical ethics committee approval was obtained for our study (Afyon Kocatepe University, 2017-194).

\section{Results}

Fifty students participated in the study (31 female, 19 male) and the data were evaluated on 100 forms (Figure 1). While “Dead human bodies shown in public areas without educational purposes affect cadaver donation adversely" is the opinion most adopted by the participants before cadaver training $(4.52 \pm 0.79)$, the least adopted opinion is "Whatever the purposes are, a dead person's body should not be used for training" (1.96 \pm 0.7$)$. While "Human is valuable asset.

\section{Demographic distribution of the participants}

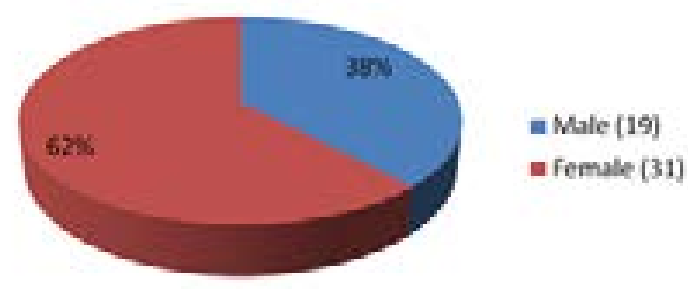

Figure 1. Demographic distribution of the participants 
Table 1. The expressions in the Data Form and the frequency, percentage, mean and standard deviations of the answers given by the students

\begin{tabular}{|c|c|c|c|c|c|c|c|c|}
\hline \multirow{2}{*}{ STATEMENTS } & & \multicolumn{5}{|c|}{ Frequency (\%) } & \multirow{2}{*}{ Mean \pm SD } & \multirow{2}{*}{$P$ value } \\
\hline & & 1 & 2 & 3 & 4 & 5 & & \\
\hline \multirow{2}{*}{$\begin{array}{l}\text { Human is valuable asset. Therefore; while person was both } \\
\text { alive or after death, value and respect must be given to the } \\
\text { human body. }\end{array}$} & B & $2(4)$ & - & $3(6)$ & $12(24)$ & $33(66)$ & $4.48 \pm 0.93$ & \multirow[b]{2}{*}{0.468} \\
\hline & A & $2(4)$ & - & $3(6)$ & $12(24)$ & $39(78)$ & $4.60 \pm 0.93$ & \\
\hline \multirow{2}{*}{$\begin{array}{l}\text { Whatever the purposes are, a dead person's body should not } \\
\text { be used for training. }\end{array}$} & B & $13(26)$ & $26(52)$ & $11(22)$ & - & - & $1.96 \pm 0.70$ & \multirow{2}{*}{0.305} \\
\hline & A & $12(24)$ & $35(70)$ & $2(4)$ & - & $1(2)$ & $1.86 \pm 0.67$ & \\
\hline \multirow{2}{*}{$\begin{array}{l}\text { Experience of working with cadavers contributes to the } \\
\text { medical students to get rid of prejudices about the dead } \\
\text { human body and the death itself. }\end{array}$} & B & $2(4)$ & $3(6)$ & - & $19(38)$ & $15(30)$ & $3.84 \pm 1.06$ & \multirow[b]{2}{*}{0.224} \\
\hline & $\mathbf{A}$ & - & $2(4)$ & $7(14)$ & $26(52)$ & $15(30)$ & $4.08 \pm 0.78$ & \\
\hline \multirow{2}{*}{$\begin{array}{l}\text { Within the framework of the right of privacy, to cover the } \\
\text { face of cadaver during the dissection is a humanitarian } \\
\text { curtousy and respect that should not to be neglected. }\end{array}$} & B & - & $6(12)$ & $9(18)$ & $16(32)$ & $19(38)$ & $3.96 \pm 1.03$ & \multirow[b]{2}{*}{0.153} \\
\hline & $\mathbf{A}$ & $4(8)$ & $7(14)$ & $6(12)$ & $18(36)$ & $15(30)$ & $3.66 \pm 1.27$ & \\
\hline \multirow{2}{*}{$\begin{array}{l}\text { During the dissection-demonstration, cadaver is only an } \\
\text { object. Cadaver is supposed to be adopted and seen only as } \\
\text { an object. }\end{array}$} & B & $7(14)$ & $8(16)$ & $14(28)$ & $15(30)$ & $6(12)$ & $3.10 \pm 1.23$ & \multirow{2}{*}{0.583} \\
\hline & $\mathbf{A}$ & $3(6)$ & $12(24)$ & $13(26)$ & $13(26)$ & $9(18)$ & $3.26 \pm 1.19$ & \\
\hline \multirow{2}{*}{$\begin{array}{l}\text { Taking a souvenir photo with cadaver by students should } \\
\text { not be objected. }\end{array}$} & B & $22(44)$ & $7(14)$ & $7(14)$ & $6(12)$ & $8(16)$ & $2.42 \pm 1.54$ & \multirow{2}{*}{0.167} \\
\hline & A & $17(34)$ & $8(16)$ & $4(8)$ & $8(16)$ & $13(26)$ & $2.84 \pm 1.66$ & \\
\hline \multirow{2}{*}{$\begin{array}{l}\text { Before facing with cadavers first, a lecture should be given } \\
\text { to the students to make them prepared emotionally and } \\
\text { intellectually for it. }\end{array}$} & в & $2(4)$ & $10(20)$ & $6(12)$ & $25(50)$ & $7(14)$ & $3.50 \pm 1.09$ & \multirow[b]{2}{*}{0.157} \\
\hline & $\mathbf{A}$ & $3(6)$ & $8(16)$ & $20(40)$ & $17(34)$ & $2(4)$ & $3.14 \pm 0.95$ & \\
\hline \multirow{2}{*}{$\begin{array}{l}\text { The studies on cadavers do not provide a significant } \\
\text { contribution to the physiotherapy students in terms of } \\
\text { improving their medical-surgical skills. }\end{array}$} & B & $16(32)$ & $22(44)$ & $6(12)$ & $5(10)$ & $1(2)$ & $2.06 \pm 1.02$ & \multirow{2}{*}{0.063} \\
\hline & A & $10(20)$ & $20(40)$ & $6(12)$ & $14(28)$ & - & $2.48 \pm 1.11$ & \\
\hline \multirow{2}{*}{$\begin{array}{l}\text { Working with cadavers is also important not only in terms of } \\
\text { studying the human body, but also acquiring a professional } \\
\text { physiotherapist identity for physiotherapy students. }\end{array}$} & B & $3(6)$ & $3(6)$ & $1(2)$ & $25(50)$ & $18(36)$ & $4.04 \pm 1.09$ & \multirow[b]{2}{*}{0.185} \\
\hline & $\mathbf{A}$ & $1(2)$ & $4(8)$ & $4(8)$ & $35(70)$ & $6(12)$ & $3.82 \pm 0.82$ & \\
\hline \multirow{2}{*}{$\begin{array}{l}\text { It is a student right to refuse to work on cadavers because of } \\
\text { religious and conscientious reasons and it must be respected. }\end{array}$} & B & $2(4)$ & $4(8)$ & $9(18)$ & $21(42)$ & $14(28)$ & $3.82 \pm 1.06$ & \multirow{2}{*}{0.260} \\
\hline & $\mathbf{A}$ & $1(2)$ & - & $5(10)$ & $35(70)$ & $9(18)$ & $4.02 \pm 0.68$ & \\
\hline \multirow{2}{*}{$\begin{array}{l}\text { Dead human bodies shown in public areas without } \\
\text { educational purposes affect cadaver donation adversely. }\end{array}$} & B & $1(2)$ & $1(2)$ & - & $17(34)$ & $31(62)$ & $4.52 \pm 0.79$ & \multirow{2}{*}{$0.037^{*}$} \\
\hline & A & $2(4)$ & $1(2)$ & $4(8)$ & $23(46)$ & $20(40)$ & $4.16 \pm 0.95$ & \\
\hline \multirow{2}{*}{$\begin{array}{l}\text { Three-dimensional modeling or working on the human } \\
\text { models is more useful than studying on cadavers in } \\
\text { anatomy education. }\end{array}$} & в & $10(20)$ & $18(36)$ & $12(24)$ & $7(14)$ & $3(6)$ & $2.50 \pm 1.15$ & \multirow{2}{*}{$0.005^{*}$} \\
\hline & $\mathbf{A}$ & $1(2)$ & $16(32)$ & $14(28)$ & $13(26)$ & $6(12)$ & $3.14 \pm 1.07$ & \\
\hline
\end{tabular}

*; A statistically significant difference is observed in the opinion in the statement, A; after cadaver experience, B; after cadaver experience, \%; Percentage SD; Standart deviation, 1;

Strongly disagree, 2; disagree, 3; Undecided, 4; Agree, 5; Strongly agree

Therefore; while person was both alive or after death, value and respect must be given to the human body" is the opinion most adopted by the participants after cadaver training $(4.6 \pm 0.93)$, the least adopted opinion is "Whatever the purposes are, a dead person's body should not be used for training" $(1.86 \pm 0.67)$, (Table 1$)$.

A statistically significant difference was observed in the "Dead human bodies shown in public areas without educational purposes affect cadaver donation adversely" opinion when the survey data before and after cadaver training were compared $(p=0.037)$ and there has been a decrease in the number of people who agree with this opinion. In addition, a statistically significant difference was observed in the "Threedimensional modeling or working on the human

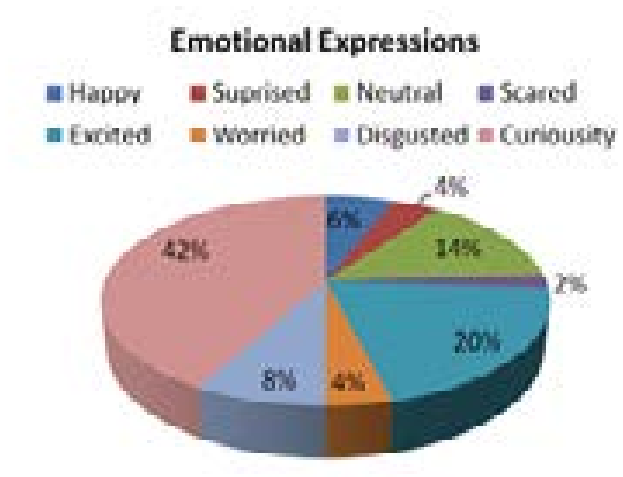

Figure 2. The emotional reactions of physiotherapy students in their first cadaver experience. 
models is more useful than studying on cadavers in anatomy education" opinion $(\mathrm{p}=0.005)$ and it was found that the agreement to this opinion increased. "Curiosity" was the most salient emotion with a rate of $42 \%$ in the responses to the emotional expression at the time of encountering with the cadaver. The inclusion of the expressions "Excited" (20\%) and "Neutral" $(14 \%)$ following this expression show us that positive opinions majority (Figure 2).

\section{Discussion}

The opinion about worthiness and dignity of human and human body is admitted by the participants. Expression with the highest mean value in terms of the degree of adoption support this opinion. The main controversy under this issue is that the dead human body is seen as educational material. Is a "thing" as educational material merely an object related with no moral relevance? It was determined in a study in England, 26\% of the students stated that the cadaver was just an object, an undecided attitude about this issue was taken $26 \%$ of them [12]. The perceptions of students and lecturer are also different from each other on this issue [11]. While anatomists tend to be indecisive and accepting in the approach of considering the cadaver as only an object in the educational process [10], the approach of students considering cadaver only as an object is more majority in this study. Even the experiences with cadavers, students could not affect their opinions on this issue. It is possible to say that the reason for these differences with the literature are the differences in perception and professionalism between the lecturers and those who have recently faced cadaver experience.

Performing some manipulative operations on cadaver and/or interacting with cadaver for educational purposes is sometimes not a situation that people can easily overcome. The refusal to work on cadavers is a students' right that should be respected if students do not want, and the opinions of these students on this issue are clearly seen in our study. At this point, when viewed from the student's perspective, it should not be overlooked that psychological attitudes or religious belief of students may sometimes take priority over education. In addition, another result of our study is that the integration of a course aimed at emotionally and intellectually preparing for the cadaver experience into anatomy education should be one of the primary educational parameters.
Being a tool (model) for an important practice such as anatomy education and wanting to contribute to this process can be regarded as virtuous behavior. It is also worth emphasizing that people who have a strict approach to the worhty of human beings and the human body defend the thesis that their bodies are too valuable to be used as cadavers, but these people do not respect their own bodies as required. There are some studies emphasizing their contribution to education and the values of the human bodies used in dissection laboratories [4, 10, 13]. In our study, the value attributed to cadavers was clearly demonstrated, and the opinion that cadavers should not be displayed in public places for non-educational purposes and that this approach would negatively affect cadaver donation was majority. This result is due to the importance of cadaver education which is an indispensable part of the anatomy education and the empathy the students establish with the person who donated herself/himself as a cadaver.

Lewis et al. [14], state that detailed anatomical knowledge yields a high level of tissue and organ manipulation by improving the efficiency and safety of a surgeon in order to heal and save a patient. They argue that while anatomy can also be learned from textbooks, atlases, computer models and projections, dissection is the most efficient method. Based on these arguments, they concluded that dissectible cadavers prepared fresh or prepared with alternative methods will increase knowledge and skill in surgical education and specific surgeries. In addition to all these mentioned elements, it is reported that learning a new procedure with daily practices on living beings is quite dangerous for education and that practices on cadavers increase the education experiences.

In our study, before cadaver experience, students opposed the opinion that three-dimensional modeling or working on the human models is more useful than studying on cadavers in anatomy education, while it was observed that this approach was completely reversed after cadaver experience. It is noteworthy that the participants tend to prefer alternative methods, although they have received a cadaver course. It can be said that this tendency puts forward the necessity of studying and discussing on different education models that include cadaver. Similar results were associated in a study in which such a different model was put on the agenda and evaluated [15]. As a result of the survey study conducted by Yavuz et al. [16] on medical faculty students, they reported that 
cadaver dissection is a better education method for students than models, facilitates the understanding of course subjects, and is an important tool in associating basic sciences with clinical sciences In addition, they also concluded that the students saw the cadavers in a more respectable position than the other dead and that a lesson that prepares students to encounter cadavers emotionally and intellectually should reduce the fear and stress that will be experienced in students. They also reported that cadaver dissection is a positive factor in the formation of doctor identity. Three possible reasons underlying students' negative attitudes towards cadaver in anatomy education can be listed as follows: In anatomy practical courses experience of watching and seeing the cadaver under the control of a lecturer rather than contact with the cadaver, psychological and physiological difficulties of working with cadavers, the cadaver was not respected as much as they expected. Considering the fact that the aforementioned reasons can be increased, we would like to bring to the attention of anatomy lecturers that physiotherapy students want to work with alternative learning models besides cadavers.

There is a common positive opinion that working with cadavers will contribute to the process of gaining the identity of a physiotherapist as well as learning human anatomy. However, it should not be overlooked that lecturers and students have different approaches in this regard. In our study, students supported this opinion, but remain in the middle in terms of importance. However, according to the approach of the lecturers, this issue is much more important [10, 13, 17-21]. In fact, there was nothing strange with this situation. Although the students also think in parallel with the lecturers on this issue, they do not only express strong enough opinion on the importance of the subject [20]. People who have not yet completed the education process cannot be expected to have a perspective with a broad perspective about the outcomes of this course as much as the lecturers. The fact that the students agree with the lecturers about their contribution to the physiotherapist identity before and after cadaver course is an indication of the adoption of a professional identity and value, which is one of the main goals of education, for both parties.

\section{Conclusion}

Physiotherapy students care about the cadaver in terms of its humanitarian aspect and worth, and attribute a special worth to it in terms of contributing to anatomy education. Students who study on cadavers tend to adopt cadavers as an educational material. Students respect the cadaver as the body of a dead person. Before the cadaver experience, physiotherapy students have a similar opinion to anatomists and medical faculty students with regard to on the acceptance of the cadaver as an educational material and the superiority of cadaver over 3-dimensional modeling and plastic models. However, after the cadaver experience significant differences were found in these thoughts. The emotional reactions of physiotherapy students to the cadaver did not reveal a traumatic picture, on the contrary, they showed a curiosity and a desire to learn about the dead human body.

Ethical debates about the use of cadavers in anatomy education for years continue with the intervention of different approaches. This study, which focuses on the students' perspective on cadavers, which is an object of the health-related education process for lecturers, is expected to serve as a mirror to the anatomy education of our country from a different perspective. It is thought that conducting more studies on cadaver use, anatomy education and their ethical dimension and evaluating the subject from different perspectives can bring different approaches to anatomy education.

\section{Acknowledgments}

This study was presented as a poster as a summary text at the 18th National Anatomy Congress, 25-27, September 2017; Bolu, Turkey.

\section{Funding}

The authors declared that this study has no financial support.

\section{Conflict of interest}

The author(s) declared no potential conflicts of interest with respect to the research, authorship, and/ or publication of this article.

\section{References}

1. Gurpinar MA, Gurpinar E, Songur A, Vitrinel A. Mezuniyet öncesi tıp e itimi ulusal çekirdek e itim programı-2014; 1984.

2. Mc lachlan JC, Patten D. Anatomy teaching: Ghost of the post, present and future. Med Educ. 2006;4:243-53. https://doi. org/10.1111/j.1365-2929.2006.02401.x.

3. Cetkin M, Turhan B, Bahsi I, Kervancioglu P. The opinions of medicine faculty students about anatomy education. Gaziantep Med J. 2016;22(2):82-8. https://doi.org/10.5578/GMJ.32156. 
4. Kawashiro Y, Anahara R, Kohno T, Mori C, Matsuno Y. Attitudes of healthcare students on gross anatomy laboratory sessions. Anat Sci Educ. 2009;2:273-9. https://doi.org/10.1002/ase.116.

5. Sayek I, Odabasi O, Kiper N. Türk Tabipleri Birli i Mezuniyet Öncesi Tıp E itimi Raporu- 2010. Ankara: Türk Tabipleri Birli i Yayınları; 2010.

6. Hasan T. Is Dissection Humane? J Med Ethics Hist Med. 2011;4:4.

7. Hildebrandt $\mathrm{S}$. What is happening in our anatomical dissection rooms? Clin Anat. 2014;27(6):833-4. https://doi.org/10.1002/ ca. 22396 .

8. Sehirli US, Saka E, Sarikaya O. Attitudes of Turkish anatomists toward cadaver donation. Clin Anat. 2004;17:677-81. https:/ / doi. org/10.1002/ca.20056.

9. Celik N, Celik S, Uysal C. Using of cadaver in anatomy education from past to present: Review. Turkish Clin J Med Ethics. 2012;20(3):179-85.

10. Ogenler O, Kara A, Kadioglu S, Ozturk H, Sungur MA. Opinions of a group of anatomy instructor on cadaver and utilization of cadaver in anatomy teaching. Turkish J Bioethics. 2014;1:57-68. https://doi.org/10.5505/tjob.2014.29292.

11. Erbay H, Bilir A, Gonul Y, Turamanlar O, Songur A. Medical students' perception of cadaver and, their attitudes towards using the cadaver in education. Turkish J Bioethics. 2015;2(1):63-72. https://doi.org/10.5505/tjob.2015.14633.

12. Quince TA, Barclay SI, Spear M, Parker RA, Wood DF. Student attitudes toward cadaveric dissection at a UK medical school. Anat Sci Educ. 2011;4(4):200-7. https:/ / doi.org/10.1002/ase.237.

13. 13. Cahill KC, Ettarh RR. Attitudes to anatomy dissection in an Irish medical school. Clin Anat. 2009;22(3);386-91. https://doi. org/10.1002/ca.20777.

14. Lewis CE, Peacock WJ, Tillou A, Hines OJ, Haatt JR. A novel cadaver-based educational program in general surgery training. J Surg Educ. 2012;69(6):693-8. https://doi.org/10.1016/j. jsurg.2012.06.013.

15. 1Topal AD, Ocak MA. The effect of the anatomy course prepared by the blended learning environment $\mathrm{o}$
students' academic achievement. Educ Technol Theroy Prac. 2014;4(1):1-8. https://doi.org/10.17943/etku.73155.

16. Yavuz F, Ertekin T, Elmali F, Ulger H. Attitudes of pre-clinical and clinical stage medical school students toward using cadaver in anatomy education. J Health Sci. 2017;26(3):227-32.

17. Marks SC, Bertman SL, Penney CJ. Human anatomy: A foundation for education about death and dying in medicine. Clin Anat. 1997;10:118-22. https://doi.org/10.1002/(SICI)10982353(1997)10:2<118: AID-CA8>3.0.CO;2-R.

18. Rizzolo LJ. Human Dissection: An approach to interweaving the traditional and humanistic goals of medical education the anatomical record. New Anat. 2002;269:242-8. https://doi. org/10.1002/ar.10188.

19. Arráez-Aybar LA, Castaño-Collado G, Casado-Morales MI. Dissection from the Spanish anatomist's perspective: Aims, attitudes, and related aspects. Anat Rec B New Anat. 2004;281(1):15-20. https://doi.org/10.1002/ar.b.20036.

20. Saylam C, Coskunol H. Orientation lesson in anatomy education. Surg Radiol Anat. 2005;27:74-7. https:/ /doi.org/10.1007/s00276004-0285-4.

21. Turan-Ozdemir S, Cankur NS, Kurt MA. Medical students' opinions on anatomy practicals: A questionnaire sample. Uludag Med J. 2001;27:1-8. 